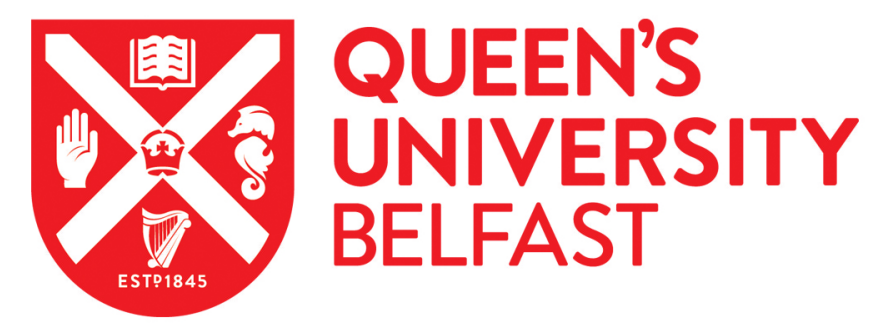

\title{
Oribatid mites show how climate and latitudinal gradients in organic matter can drive large-scale biodiversity patterns of soil communities
}

Caruso, T., Schaefer, I., Monson, F., \& Keith, A. M. (2019). Oribatid mites show how climate and latitudinal gradients in organic matter can drive large-scale biodiversity patterns of soil communities. Journal of Biogeography, 46(3), 611-620. https://doi.org/10.1111/jbi.13501

Published in:

Journal of Biogeography

Document Version:

Peer reviewed version

Queen's University Belfast - Research Portal:

Link to publication record in Queen's University Belfast Research Portal

Publisher rights

(c) 2018 John Wiley \& Sons Ltd.

This work is made available online in accordance with the publisher's policies. Please refer to any applicable terms of use of the publisher.

\section{General rights}

Copyright for the publications made accessible via the Queen's University Belfast Research Portal is retained by the author(s) and / or other copyright owners and it is a condition of accessing these publications that users recognise and abide by the legal requirements associated with these rights.

Take down policy

The Research Portal is Queen's institutional repository that provides access to Queen's research output. Every effort has been made to ensure that content in the Research Portal does not infringe any person's rights, or applicable UK laws. If you discover content in the Research Portal that you believe breaches copyright or violates any law, please contact openaccess@qub.ac.uk. 
Oribatid mites show how climate and latitudinal gradients in organic matter can drive large-scale biodiversity patterns of soil communities

Short running title: Macroecological determinants of soil animals

7

Authors: Tancredi Caruso ${ }^{\mathrm{a}}$, Ina Schaefer ${ }^{\mathrm{b}}$, Frank Monson ${ }^{\mathrm{c}}$, Aidan M Keith ${ }^{\mathrm{d}}$

a School of Biological Sciences and Institute for Global Food Security, Queen's University Belfast. Medical Biology Centre, 97 Lisburn Road, Belfast BT9 7BL, Northern Ireland, UK

bJ.F.Blumenbach Institute of Zoology and Anthropology University of Göttingen, Untere Karspüle 2, 37073 Göttingen, Germany

${ }^{\mathrm{c}}$ Associate, World Museum Liverpool, William Brown Street, Liverpool, L3 8EN

${ }^{d}$ Centre for Ecology \& Hydrology, Lancaster Environment Centre, Library Avenue, Bailrigg, Lancaster LA1 4AP, UK

Corresponding Author: Tancredi Caruso, t.caruso@qub.ac.uk , + 44 (0) 2890972271

\section{Acknowledgments}

TC and IS were supported by the project SENSE (Structure and Ecological Niche in the Soil Environment; EC FP7 - 631399 - SENSE). We thank AG Scheu (University Göttingen) for kindly providing sequences of Brachychthoniidae specimens. We acknowledge the UKCP09 data made freely available by the Met Office and supported by the Department for Environment, Food and Rural Affairs (Defra). We also wish to thank all those responsible for coordinating and conducting the 1998 Countryside Survey and subsequent processing of samples. We thank three anonymous reviewers for their constructive comments. 


\section{Abstract}

Aim: The factors determining spatial distributions and diversity of terrestrial invertebrates are typically investigated at small scales. Large-scale studies are particularly missinglacking for soil animals, which control microbial communities and represent one of the most diverse yet poorly known animal assemblages. Here, we analyzed a major group (Oribatida) to test whether belowground macroecological patterns can be predicted by climatic variables, vegetation, and large-scale variation in key soil properties.

Location: we modelled the multivariate distribution of more than 100 species using biodiversity data collected across Great Britain in the framework of the Countryside Survey (http://www.countrysidesurvey.org.uk).

Methods: We analysed species-level data from 582 samples collected across 162 hectads $(10 \times 10 \mathrm{~km})$ covering the largest possible range of vegetation types, soil properties and climatic conditions within GB. We created the first large-scale maps of soil animal diversity metrics at the GB scale, including novel estimates of metrics of phylogenetic diversity. Using structural equation modelling, we quantified the direct and indirect effects of location (latitude, longitude), plant community structure, and abiotic factors such as precipitation on species composition, richness, and phylogenetic diversity.

Results: We found that variation in species composition follows a latitudinal gradient with diversity generally increasing northward. The latitudinal variation in species composition drives phylogenetic diversity via changes in both species richness and phylogenetic distance between species. This gradient is mostly determined by latitudinal variation in precipitation and organic matter, which were very good predictor of species composition. Precipitation and organic matter were, however, relatively weak while statistically significant predictors of diversity metrics.

Conclusions: Past studies have emphasized the unpredictability of species distributions and variation in species composition in hyper diverse soil animal communities. However, past studies were conducted at small scales, where stochastic factors may weaken the signal of deterministic factors. Oribatid mites in our study show for the first time that large scale latitudinal gradients in climate and organic matter predict not only variation in species composition but also taxonomic and phylogenetic diversity of soil animal communities.

Keywords: soil macroecology; animals; diversity; distribution; community phylogenetics; Oribatida 


\section{Introduction}

In the last two decades, one of the major goals of ecology has been to understand the relative roles of the many factors that structure ecological communities in space and time but the majority of studies have focused on aboveground communities, particularly plant communities (Chesson, 2000; Clark \& McLachlan, 2003; Hubbell, 2005; Levine \& HilleRisLambers, 2009). More recently, ecologists have started to better investigate the interactions between aboveground and belowground communities and how these interactions drive the composition and diversity of both communities (Kardol et al., 2006; Van Der Heijden et al., 2008; de Vries et al., 2012; Prober et al., 2015). Traditionally, most studies investigating aboveground-belowground linkages have been conducted at relatively local spatial scales but some regional and global scale analyses of soil microbial communities have shed light on the large scales determinants of these communities (Fierer et al., 2009; de Vries et al., 2012; Ramirez et al., 2014). Local and fine scale variation seems mostly due to interactions determined by the patchy distribution of resources and plant species (Bezemer et al., 2010; Thomson et al., 2010) while spatial gradients in vegetation types and abiotic factors such as $\mathrm{pH}$ and climatic conditions are the major correlates of microbial distribution at regional scales (Fierer et al., 2009; Griffiths et al., 2011). Protists, too, follow similar macroecological patterns (Soininen, 2011). For some groups such as arbuscular mycorrhizal fungi (AMF), global studies have started to reveal the relative roles of local, regional and historical factors on community structure and diversity (Davison et al., 2015) but for soil animals large-scale studies are missing despite some synthesis data having provided insight in the macroecology of soil arthropods, nematodes and oligochaetes (Decaëns, 2010; Brusaard et al., 2012; Nielsen, 2014). Studies focusing on selected assemblages at relatively local scales (Lindo \& Winchester, 2009; Nielsen et al., 2010; Caruso et al., 2011) have shown that, similarly to microbial communities, soil animal communities are structured at multiple spatial scales, with many species being dispersallimited over certain scales (Ettema \& Wardle, 2002; Wardle, 2006) and soil environmental 
heterogeneity being high already at very small scale (e.g. $<100 \mathrm{~cm}$; Ettema \& Wardle 2002).

This small scale heterogeneity promotes community diversity in both animals and microbes and is mostly due to small scale variation in soil properties such as $\mathrm{pH}$, the concentration of organic matter and key nutrient such as $\mathrm{P}$ and $\mathrm{N}$, and also structural variation in soil such as variation in the physical distribution of aggregates (Dumbrell et al., 2010; Nielsen et al., 2010). Nevertheless, much spatial variation in the structure and diversity of soil communities, especially animals, is often left unexplained by variation in environmental variables or other biotic factors. Previous studies have hypothesised that stochastic population dynamics, including dispersal limitation, may sometimes play a major role in this variation (Lindo \& Winchester, 2009; Caruso et al., 2011). At large scales, the few studies available on soil animals have concentrated on classical macroecological patterns such as species-area relationships, altitudinal and latitudinal gradients in diversity and some insight on patterns of phylogenetic diversity (see review in Brusaard et al., 2012) but most datasets focused on the highest taxonomic ranks (e.g., family or class level; Nielsen, 2014) or, as noted by Decaëns, (2010) are biased in terms of sampling efforts towards temperate countries, and in general lack the resolution necessary to disentangle the contribution of multiple factors at multiple spatial scales. The only quantitative study on the regional variation of soil animal communities at the species level (Zaitsev et al. 2013) showed that studies conducted at relatively small scales cannot capture the long-term effects of the historical processes that contribute to large scale gradients in species richness and community composition. Overall, large-scale studies that help disentangle the roles of abiotic and biotic factors that structure soil communities at regional scales are in their infancy.

Here we focused on a unique dataset of the species of oribatid mites collected during the first assessment of soil biodiversity across Great Britain undertaken in 1998 (known as the GB Countryside Survey or CS: http://www.countrysidesurvey.org.uk). This survey produced a baseline dataset across all major soil types and habitats (Black et al., 2002) and showed that populations of microbes and microarthropods varied across major environmental zones, 
vegetation classes and soil types (Black et al., 2003; Griffiths et al., 2011; Keith et al., 2015). Oribatid mites (Acari, Acariformes) are a cornerstone of soil food webs worldwide: over 10,000 species have been described and they can reach densities of up to $400,000 \mathrm{ind} . / \mathrm{m}^{2}$ in forest soils, although they occur in all biomes including continental Antarctica (Coleman et al., 2004). Oribatid mites are one of the most ancient groups of terrestrial animals and have been part of the soil food webs ever since soil have appeared on the geological record about 400 mya (Shear et al., 1984; Norton et al., 1988). They appear for the first time in the fossil record of the Devonian site of Rhynie Chert (407-397 mya, Aberdeenshire, Scotland) although a relatively recent molecular clock suggests a much earlier origin (Schaefer et al., 2010). For all these reasons, oribatid mites provide an excellent model to analyze the role of abiotic and biotic factors in structuring diversity and composition of belowground animals at regional scales. We used the dataset of oribatid mites to conduct a species-level analysis of the determinants of community structure and diversity of this major group of soil animals.

The CS is a unique audit of vegetation, soils, habitats and landscape across GB that began in 1978 (Firbank et al., 2003; Keith et al. 2015). Using a spatially explicit approach, we created the first maps of diversity metrics at the GB scale for a major soil animal group, including the first estimates of phylogenetic diversity (Faith, 1992; Cadotte et al., 2010) and used structural equation modelling (Grace, 2006) to estimate the direct and indirect effects of location (latitude, longitude), abiotic factors such as precipitation, and plant community structure on oribatid mite species composition and diversity. We hypothesized that largescale gradients in this belowground community are directly driven by large-scale gradients in abiotic factors (e.g., climatic variables) but also via the effects of these factors on plant community structure and edaphic properties such as organic matter. 


\section{Methods}

\section{Database Background background}

The data analysed in this study were collected in the framework of the Country Survey audit (Firbank et al., 2003; Keith et al. 2015). This environmental audit is based on a stratification of GB into land classes, each land class being characterised by a combination of climate, altitude and location (Firbank et al., 2003; Sheail \& Bunce, 2003). Each sampling location was assigned a Broad Habitat $(\mathrm{BH})$ and-an Aggregate Vegetation Class (AVC)-BH is a Glassification consisting of 27 habitats that are used in the Land Cover Map accounting for the entire land surface of $G B$, and; $A V C$ is a high-level grouping of vegetation types produced from a classification of plant communities from the original CS vegetation plots and includes eight categories that group common habitats (crops and weeds, tall grass and herb, fertile grassland, infertile grassland, lowland woodland, upland woodland, moorland-grass mosaic, and, heath and bog (Bunce et al., 1999). Specifically, we analysed 582 samples mostly collected between 29 May and 28 October in 1998 with some samples collected between June and August in 1999. The samples analysed in this study were collected across $16210 \times 10 \mathrm{~km}$ plots (hectads), with an average of 4 locations sampled within each hectad. Each sample location was associated with information on vegetation, soil properties and land-use, produced during CS. For the collection of each soil sample, surface vegetation was removed leaving the litter layer intact and a soil core (4 cm diameter, $8 \mathrm{~cm}$ depth) was taken. Cores were placed immediately in cool boxes and sent to the laboratory at the Centre for Ecology \& Hydrology Lancaster for extraction of invertebrates.

\subsection{Oribatid extraction and identification}

Cores were processed over five days using a dry Tullgren extraction method and all invertebrate specimens collected into $70 \%$ ethanol preservative (Emmett et al., 2010) . Once collected, the soil invertebrates were identified to broad taxa, separated and counted under a 
stereomicroscope. Specimens of Acari (mites) from each extract were removed into another vial and sent for separation and identification of oribatid mites species. Specimens were identified at $\times 400$ magnification and, where necessary, were cleared for $24 \mathrm{~h}$ using lactic acid at room temperature before being mounted in glass cavity slides. The unpublished monograph of British oribatid mites by M. Luxton and other specialist primary literature were used to identify oribatid mites to the species level; identifications have since been checked against Weigmann, (2006). Weigmann (2006) plus several other specialist publications were also used to define geographic distributions and ecological traits of the taxa. Plot codes,

Oribatid oribatid species records and taxonomic details were then collated into a dataset that is available upon request from the NERC Environmental Information Centre-(see-Keith et al. 2018 for details to access the data).

\subsection{Associated environmental data}

Existing data on soil (Black et al. 2016); and vegetation (Barr et al. 2014) and habitat data from CS were collated for the 582 plots with oribatid mite records samples of soil fauna and are available upon request from the NERC Environmental Information Centre (see Barret al. 2014 and Black et al. 2016 for details to access the vegetation and habitat data). Soil properties were collected from a separate core taken adjacent to the core used to extract soil animals; soil data included moisture content, $\mathrm{pH}$, organic matter (loss-on-ignition), total $\mathrm{C}$ content and total $\mathrm{N}$ content. The sampling protocol and detailed methods used for these soil analyses can be found in Emmett et al. (2008) and the data are reported in more detail elsewhere (Reynolds et al., 2013). For vegetation composition, ordination scores were used from the first three axes of a Detrended Correspondence Analysis (DCA) using binary plant species data from the same plots.

Climate data associated with each sampling plot was derived from the UKCP09: Met Office gridded land surface climate observations at $5 \times 5 \mathrm{~km}$ resolution (Met Office, 2017). These 
data were used to calculate average values of mean annual temperature and mean annual rainfall for the period 1992-1997, in order to incorporate recent climatic trends.

\subsection{Statistical analyses}

\section{Community and environmental data}

Records of oribatid mites across sampling locations were collated at $10 \mathrm{~km} \times 10 \mathrm{~km} / \mathrm{hectad}$ resolution for a total of $16210 \times 10 \mathrm{~km}$ squares, and the associated environmental data were averaged at this resolution (see Barr et al. 2014, Black et al. 2016 and Keith et al. 2018 to access the data from NERG Environmental Information Contre).

We used the spatial interpolation method of kriging (Matheron, 1963; Wagner, 2003) to illustrate spatial variation in community structure and metric of diversity (see below for the metrics used). The spatial structure of the variables was quantified with the empirical semivariogram (Wagner, 2003; Bivand et al., 2008) and then fitted with a theoretical variogram model (i.e., exponential or Gaussian, or spherical models) to estimate values at unmeasured locations. We used the-R library "tgeoR", " " "maps", ' " .mapdata" 'and "'gstat" Commented [KA1]: Do these all have separate citations or do they come as one? for calculating variograms, kriging estimation and mapping of results_. See also Bivand et al. (2008) for further details.

We used a multivariate regression approach based on Principal Coordinate Analysis (Legendre \& Legendre, 1998; Borcard et al., 2004) to quantify the relative importance of location (space) and environment (temperature, plant community composition, $\mathrm{pH}$, precipitation, organic matter) on oribatid mite community structure. PCoA was applied to the Jaccard distance matrix obtained by the presence-absence distribution of species, and a distance based RDA (db-RDA) was used to estimate the effect of space and environment on the multivariate distribution of species. 
To quantify the effect of "space" (i.e., location), we used latitude, longitude and the method of principal coordinate analysis of neighbour matrices (PCNM; Borcard \& Legendre, 2002), which defines a set of spatial factors that parsimoniously account for patterns in species distribution at multiple scales. The final set of PCNM vectors was defined using a multivariate extension of the Akaike information criterion (AIC; Dray et al., 2006). Variance partitioning was computed to estimate the amount of fraction uniquely attributable to space and environment, and the variation shared between space and environment (Borcard et al., 1992; Legendre \& Legendre, 1998). Besides observed species number per hectad we also calculated species rarefaction curve (Gotelli \& Colwell, 2001) for each hectad and estimated the hectad asymptotic richness using the Chao estimator (O'Hara 2005; Chiu et al. 2014). All multivariate analyses and estimates of species richness were performed using the $\mathrm{R}$ package ‘vegan' "vegan” (Oksanen et al., 2007).

\section{Phylogenetic methods}

The phylogenetic tree was reconstructed based on 18S rDNA. Sequences were downloaded from NCBI (https://www.ncbi.nlm.nih.gov) or, if not available, were newly generated sequenced at theJ.F.Blumenbach Institute of Zoology and Anthropology, University of Göttingen.

Genomic DNA was extracted from single individuals using the DNeasy ${ }^{\circledR}$ Blood and Tissue Kit (Qiagen, Manchester, UK) following the manufacturer's protocol for animal tissue. Amplification of the $18 \mathrm{~S}$ region was performed in $25 \mu$ l volumes containing $12.5 \mu \mathrm{l}$ HotStarTaq Mastermix (Qiagen), $5 \mu$ l of template DNA, $1 \mu$ l of each primer (100 pM) and 5.5 $\mu \mathrm{l} \mathrm{H}_{2} \mathrm{O}$. Primers for PCR were 5' -TAC- CTGGTTGATCCTGCCAG-3' (forward) and 5' TAATGATCCTTCCGC AGGTTCAC-3' (reverse) (Domes et al., 2007). The PCR protocol consisted of an initial activation step at $95^{\circ} \mathrm{C}$ for $15 \mathrm{~min}, 35$ amplification cycles $\left(95^{\circ} \mathrm{C}\right.$ for 45 $\mathrm{s}, 57^{\circ} \mathrm{C}$ for $60 \mathrm{~s}, 72^{\circ} \mathrm{C}$ for $60 \mathrm{~s}$ ) and a final elongation step at $72^{\circ} \mathrm{C}$ for $10 \mathrm{~min}$. All PCR 
products were visualized on a 1\% agarose gel, purified with the QIAquick PCR Purification Kit (Qiagen), and sequenced by Microsynth Seqlab (Göttingen, Germany), using the additional sequencing primers 18S554f 5'-AAGTCTGG TGCCAGCAGCCGC-3' , 18S1282r 5'-TCACTCCACCAACTA AGAACGG C-3', 18S1150f 5' -

\section{ATTGACGGAAGGGCACCACCAG-3' and 18S614r 5'- TCCAACTACGAGCTTTTTAACC-3'} (Domes et al., 2007). In total, we used 51 species for the phylogenetic tree, including four outgroup taxa. All taxa and accession numbers are available at GenBank (Supporting Information, Appendix S1, Table S1). We aimed to represent each family in the GB dataset with at least one species but very few rarer species could not be represented either because sequences are not available in public database or because we did not have sufficient material to sequence them. In total, the dataset represents 31 out of the 34 families found in the GB dataset and the three families we could not represent were very rare and present with very low abundances. Sequences were assembled and ambiguous positions were corrected in Sequencher 5.3 (Gene Codes Corporation, Ann Arbor, Michigan, USA) and aligned using ClustalW implemented in BioEdit v7.0.1 (Hall, 1999) with the multiple alignment parameters gap opening $=30$ and gap extension $=0.3$.

The alignment was truncated to the shortest sequence resulting in a length of $1,743 \mathrm{bp}$ including gaps. Evolutionary model parameters were determined with jModelTest v2.0 (Guindon \& Gascuel, 2003; Darriba et al., 2012) using the AIC. The best-fit model for sequence evolution for $18 \mathrm{~S}$ was GTR $+\mathrm{I}+\mathrm{G}$. The phylogenetic tree was constructed in $\mathrm{R}$ using packages 'ape' (Paradis et al., 2004) and 'phangorn' "ape" and "phangorn" (Paradis et al., 2004; (Schliep 2011, Schliep et al., 2017) using Maximum Likelihood and 1,000 bootstrap replicates. The phylogenetic tree was reduced to 31 oribatid mite taxa representing one species per family using the drop.tip function, the $\mathrm{R}$ script is provided in the Appendix S1 (Supporting Information)

We used this oribatid mite phylogenetic tree to calculate metrics of phylogenetic diversity. The resolution of the available phylogenetic information constrained us to calculate these 
metrics at the family level. Specifically, we calculated the Faith's Index PD (Faith, 1992) and two distance based metrics: the mean phylogenetic distance (MPD) and the mean nearest taxon distance (MNTD). The index PD estimates the phylogenetic diversity of a community as the sum of the tree branch lengths connecting all species in the assemblage and as such it can be considered an estimate of point diversity with two components: species richness and amount of phylogenetic information across all the species in the assemblage. The indices MPD and MNTD measure the average phylogenetic distance between species in an assemblage. The MPD is based on mean distance of any taxon from every other taxon while MNTD is average of the distance between any taxon and its closest relative. Community phylogenetic metrics were calculated using the R package "picante" and other packages ('ape' and 'phytools') that support phylogenetically informed statistical analyses ('ape', "phylobase', 'adephylo', 'phytools' "ape", "phylobase","adephylo","phytools"; Kembel Paradis et al., 2004, Kembel 2010, Revell 2012, Swenson, 2014)

\section{Structural equation modelling (SEM)}

In order to quantify direct and indirect effects of climatic and soil variables (temperature, plant communities, $\mathrm{pH}$, precipitation, organic matter) on community species composition (PCoA ordination axes) and diversity (richness and metric of phylogenetic diversity) we used Structural Equation Modelling (Grace, 2006). We started from an a priori model (Appendix S2, Fig. S1 in the Supporting Information) assuming that latitude, longitude and elevation drive the spatial variation of climate (i.e. precipitation and temperature), which correlates with spatial variation in organic matter. The variation in climate and organic matter then drives spatial variation in oribatid mite species composition. However, other factors that may vary with latitude and longitude, including biogeographical factors, may drive the spatial distribution of oribatid species. Biogeographical factors, which are implicitly accounted for by latitude and longitude, include the major spatially structured features of the geology of Britain 
(Toghil, 2005), with northern areas (e.g, Scottish highlands) being generally older but also more affected by last glacial maxima than southern areas (e.g., southeast England). Eventually, all these environmental and geological changes in space determined spatial variation both in species composition and metrics of diversity, including species richness and phylogenetic diversity metrics that combined both richness and compositional information. Starting from this conceptual model, we fitted various versions of the model to the data until we obtained a parsimonious model that could adequately fit the data. Model fit was evaluated using the Chi-square test, and the RMSEA and CFI index, while amount of explained variation in community metrics and diversity indices (R-square) was used to measure the predictive power of the model (Grace, 2006; Shipley, 2016). SEM was performed using the R package 'lavaan' lavaan-(Rosseel, 2011).

\section{Results}

A total of 141 species were found in this study, which represented more than one third of known oribatid mites in the British Isles (Luxton, 1996) and the vast majority of belowground species (the CS survey specifically focused on soil species while oribatid mites also live on aboveground moss and tree canopy). Observed species richness ranged from 1 to 28 while the Chao's estimator ranged from 1 to 161 species. Hectads with very low species richness always included arable and very infertile grassland soil, where environmental conditions typically supported only very poor oribatid mite communities or no oribatids at all. These soils were colonised only by very few opportunistic species such as some of the species in the genera Tectocepheus, Liochthonius and Pantelozetes. On the contrary, hectads with high species richness tended to be characterised by woodland or organic soils, where oribatid mites are known to be abundant. Observed hectad species richness displayed both clear latitudinal and longitudinal gradients with hectads in north-west Scotland being richer than in south-east England (Fig. 1). Instead, Chao's estimator showed a very patchy 
distribution suggesting the existence of hotspots of species richness, mostly located in central and northern England, and Scotland (Fig. 1).

The species-area relationship was best fitted by a sigmoidal model (Fig. 2) meaning the existence of an upper limit below which species richness is relatively, but not completely, independent of area. Also, as area increases species richness is predicted to reach an upper asymptotic level (Lomolino, 2000). The classical power model and semi-log model provided a much poorer fit to the data.

The variation in oribatid mite species composition was mostly driven by the covariation between organic matter (measured as Loss-on-ignition $\Theta$ ), $\mathrm{pH}$, and precipitation and variation in plant species composition, which was almost collinear with amount of organic matter. Although both community structure and environmental variables follow clear latitudinal patterns (Fig. 3), the total amount of variance accounted for by measured environmental variables was only $8 \%$. Yet, this fraction of variation was statistically significant at $\mathrm{P}<0.05$. There was also $6 \%$ of variance accounted for by the spatially structured effect of environmental and plant variables. The pure effect of latitude, longitude and PCNMs (i.e., after removing environment) accounted only for $1 \%$ of community variance, meaning that the observed spatial variation in the assemblage is mostly co-varying with the spatial structure observed in the environmental variables (6\%).

Metrics of phylogenetic diversity showed different types of spatial patterns (Fig. 4). The Faith's index showed gradients that were highly correlated to the same ones observed for plot species richness (compare Fig. 4 with Fig. 1) while MPD and MNTD mostly reflected longitudinal gradients. MPD is higher in the North and the East while MNTD seems more variable and reaching the highest value in the South-East (Fig. 4).

Structural equation modelling indicated that models including just latitude as a descriptor of position generally outperformed models with both latitude and longitude in terms of global fit metrics. For example, all models with both latitude and longitude resulted in Chi-square with 
p-values much lower than 0.05 (i.e., model rejected) and with very poor CFI $(<0.9)$ and RMSEA (>0.2) values. We therefore retained latitude and removed longitude from the subsequent models. Although latitude could affect indices of diversity both directly and indirectly, models with a direct link between latitude and diversity indices returned very poor global fit metrics and were therefore not considered further. Details on the models considered during the SEM exercise and their performances are provided Appendix S2. The optimal model (Fig. 5) suggests that organic matter is the major driver of oribatid mite community composition and that variation in species composition determines metrics of phylogenetic diversity. Specifically, greater shifts in oribatid mite community assemblages towards that typical of heath, bog and highly organic soil, were associated with higher phylogenetics diversity (positive correlation between PCoA1 and PD) but also lower mean nearest taxon distance (negative correlation between PCoA1 and MNTD). However, there is also an indirect positive effect of PCoA1 on MNTD via PD (positive correlation between PD and MNTD). The model could account for 50,16 and $5 \%$ of variance in PCoA 1 (major changes in species composition), PD and MNTD, respectively. The full łavaan-output of the SEM is in Appendix S2 (Supporting Information)

\section{Discussion}

Soil animal assemblages tend to be very species rich even at small scales. This has been explained as an effect of the high environmental and microbiological heterogeneity that some soil can display already from the $10 \mathrm{~m}$ to the sub-metre scale (Anderson, 1975; Giller, 1996; Ettema \& Wardle, 2002; Nielsen et al., 2010). A surprisingly large fraction of the variation observed in the distribution of soil species is very often left unexplained by variation in key soil variables such as $\mathrm{pH}$ and organic C, or even pollutants (Maraun \& Scheu, 2000; Caruso et al., 2011, 2017; Maaß et al., 2015). Also, high degrees of stochasticity seem to characterise assembly dynamics of soil animals such as oribatid mites and collembolans at least at small to medium scales (Maaß et al., 2014; Dirilgen et al., 2018). Still, species 
distributions seem structured at small and medium scales even when spatial structure cannot be explained by spatial gradients in environmental variables (Caruso et al., 2011; Zaitsev et al., 2013). At the regional scale of the Netherlands, Zaitsev et al. (2013) found that oribatid mite communities significantly changed along the East-West direction in the absence of a significant variation in precipitation and mean annual temperature. However, geological age (bedrock) and amount and quality of organic matter did change from East to West supporting richer communities in the older forest sites (Zaitsev et al. 2013). Our dataset supports this idea at the much broader scale of Great Britain, which is characterised by a relationship between climatic gradients and organic matter: in Britain very organic rich soils (i.e. bogs and peatlands) are mostly foundpredominant in the North and West, and are characterised by a colder winter climate with more precipitation. Thus, as mean annual precipitation increases with latitude so does organic matter. This is reflected in our data by statistically significant, latitudinal changes in the oribatid mite communities, which prefer organic soil and woodland over low fertile grassland and cropland. Land use could also contribute to these patterns because, in GB, land is generally much more exploited for intensive farming in the south (e.g., England) than the north (Highlands in Scotland). However, our analysis independently accounted for vegetation types and latitudinal gradients in other properties and our results suggest a prominent role of organic matter per se. That means that, given the same land use and vegetation type, sites with higher organic matter are associated to specific oribatid mite composition and higher diversity overall. Species richness and metrics of phylogenetic diversities, too, follow this latitudinal gradient in community structure although metrics of phylogenetic diversity that take into account phylogenetic distance between species (MPD and MNTD) show patterns more complex than just a latitudinal gradient. The SEM showed that variation in distance based metrics of phylogenetic diversity (e.g., MNTD) seemed mostly explained by latitudinal changes in species composition rather than accumulation of species richness and phylogenetic diversity (PD). In fact, the direct and negative effect of the latitudinal changes in species composition on MNTD was statistically significant while the direct and positive effect of PD on MNTD was 
not. The negative correlation between the latitudinal gradient in oribatid mite composition and MNTD suggests that the more the oribatid community moves to the species composition typical of woodland and highly organic soils the less the phylogenetic distance is between a species and its closest relatives in the local assemblages. This result suggests a process of environmental filtering and convergence toward specific assemblages (Webb, 2000)._The SEM, however ${ }_{1}$ could explain only $5 \%$ of the variance observed in MNTD and $16 \%$ of the variance observed in PD suggesting that the measured environmental variables are generally weak predictors of these broad biodiversity metrics. On the contrary, the SEM could explain about $50 \%$ of the variance observed in the latitudinal gradient in species composition, which implies species composition is much more predictable than compound metrics of biodiversity such as phylogenetic diversity (PD). Specifically, the latitudinal changes in species composition seem best explained by latitudinal variation in organic matter and precipitations, regardless of variation in phylogenetic diversity.

Latitude directly correlates with precipitation and organic matter distribution merely because of the north-south climatic gradient. When taking into account the direct and indirect effects of latitude, precipitation and organic matter on oribatid mite species composition, the strongest effect was that of organic matter. Precipitation, too, had a statistically significant, direct effect on community structure but the effect was much smaller than that of organic matter, which is consistent with Zaitsev et al. (2013). Instead, the direct effect of latitude on species composition was small and not statistically significant, which implies that latitudinal changes in species composition are driven by latitudinal changes in other variables, namely precipitation and organic matter. Alternative SEMs that linked latitude, longitude, organic matter and precipitation directly to metrics of diversity had a very poor global fit supporting the notion that large-scale gradients in soil oribatid mite diversity are driven by the factors that drive changes in species composition. Still, changes in species composition explained only a relatively small fraction of changes in species richness and phylogenetic diversity, suggesting a potential role for smaller scale heterogeneity. This heterogeneity is not 
captured by our predictors and suggests that microscale variation in edaphic properties remain a fundamental driver of species distribution and diversity in these communities. This is confirmed by the fact that some hectads resulted to be biodiversity hotspot in terms of estimated species richness. We could not resolve the variables driving this patchy pattern but we speculate that this is driven by soil environmental heterogeneity within hectads, which could be caused by unmeasured variation in habitat fragmentation and land-use intensity (see also supplementary results in the Supporting Information, Appendix S3, Table S2)

Despite the latitudinal patterns observed in oribatid mites and contrary to what has been observed in small- and medium-scale studies (Caruso et al., 2011; Maaß et al., 2015), the investigated community had limited spatial structure, even when considering spatial variation that is not explainable by spatial structure in environmental variables. In comparison, the microbial communities of GB seem to be much more spatially structured (Griffiths et al., 2011), which suggests the interesting hypothesis of a decoupling between large-scale patterns in soil microbes and animals.

\section{Conclusions}

Latitudinal gradients in organic matter are the most important predictor of latitudinal changes in species composition of oribatid mites across the spatial extent of Great Britain. These changes partially drive variation in species richness and phylogenetic diversity but a significant fraction of the variation observed in these metrics remained unexplained, suggesting a potential role for unmeasured environmental heterogeneity at medium and small scales. Despite small and medium scale heterogeneity, macroecological patterns in this major group of soil animals are predictable by the climatic factors that control variation in plant community structure and organic matter. 
All Countryside Survey data used in this study are available from the NERC Environmental Information Data Centre. Data on oribatid mite records (https://doi.org/10.5285/05cae9ae-

86c4-4a2f-a628-6c7fd0882459) are linked to soil properties

(https://doi.org/10.5285/9d1eada2-3f8b-4a7b-a9b0-a7a04d05ff72) and vegetation

(https://doi.org/10.5285/07896bb2-7078-468c-b56d-fb8b41d47065) by unique plots codes in

each dataset. Access to spatial coordinates for plot locations in Countryside Survey is

restricted to minimise risk of compromising future surveys and preserve anonymity of

locations; plot locations at $10 \times 10 \mathrm{~km}$ resolution, required to collate oribatid records at a

hectad level and retrieve linked climatic data (Met Office), were therefore obtained under a

bespoke data licence agreement between TC and the Centre for Ecology \& Hydrology.

\section{References}

Anderson, J. (1975) The enigma of soil animal species diversity. Progress in soil zoology_Lpp.51-58. Springer.

Barr, C.J., Bunce, R.G.H., Gillespie, M.K., Howard, D.C., Maskell, L.C., Norton, L.R., Scott, R.J., Shield, E.R., Smart, S.M., Stuart, R.C., Watkins, J.W., Wood, C.M., (2014)= Countryside Survey 1998 vegetation plot data. NERC Environmental Information Data Centre. https://doi.org/10.5285/07896bb2-7078-468c-b56d-fb8b41d47065

Formatted: Font: Calibri, $11 \mathrm{pt}$

Formatted: Font: Calibri, $11 \mathrm{pt}$, Font color: Auto

Bezemer, T.M., Fountain, M.T., Barea, J.M., Christensen, S., Dekker, S.C., Duyts, H., van Hal, R., Harvey, J.A., Hedlund, K., Maraun, M., Mikola, J., Mladenov, A.G., Robin, C., de Ruiter, P.C., Scheu, S., Setälä, H., Šmilauer, P., \& van der Putten, W.H. (2010) Divergent composition but similar function of soil food webs of individual plants: plant species and community effects. Ecology, 91, 3027-3036.

Bivand, R.S., Pebesma, E.J., Gomez-Rubio, V., \& Pebesma, E.J. (2008) Applied spatial data analysis with R. Springer.

Black, H., Garnett, J., Ainsworth, G., Coward, P., Creamer, R., Ellwood, S., Horne, J., Hornung, M., Kennedy, V., \& Monson, F. (2002) MASQ: Monitoring and Assessing Soil Quality in Great Britain. Survey Model 6: Soils and Pollution. Environment Agency.

Black, H., Parekh, N., Chaplow, J., Monson, F., Watkins, J., Creamer, R., Potter, E., Poskitt, J., Rowland, P., \& Ainsworth, G. (2003) Assessing soil biodiversity across Great Britain: nationa trends in the occurrence of heterotrophic bacteria and invertebrates in soil. Journal of Environmental Management, 67, 255-266.

Black, H.I.J., Chaplow, J.S., Ainsworth, G., Coward, P.A., Creamer, R., Ellwood, S., Horne, J., Hornung, M., Kennedy, V.H., Raine, L., Osborn, D., Parekh, N.R., Parrington, J., Poskitt, J.M., Potter, E., 
Reeves, N., Rowland, A.P., Self, P., Turner, S., Watkins, J.W., Wood, C.M., Woods, C., Wright, J. (2016). Soil physico-chemical properties 1998 [Countryside Survey]. NERC Environmental Information Data Centre. https://doi.org/10.5285/9d1eada2-3f8b-4a7b-a9b0-a7a04d05ff72

Borcard, D. \& Legendre, P. (2002) All-scale spatial analysis of ecological data by means of principal coordinates of neighbour matrices. Ecological Modelling, 153, 51-68.

Borcard, D., Legendre, P., Avois-Jacquet, C., \& Tuomisto, H. (2004) Dissecting the spatial structure of ecological data at multiple scales. Ecology, 85, 1826-1832.

Borcard, D., Legendre, P., \& Drapeau, P. (1992) Partialling out the Spatial Component of Ecological Variation. Ecology, 73, 1045-1055

Brusaard, L., Aanen, D.K., Briones, M.J.I., Decaëns, T., De Deyn, G.B., Fayle, T.M., James, S.., \& Nobre, T. (2012) Biogeography and phylogenetic community structure of soil invertebrate ecosystem engineers: global to local patterns, implications for ecosystem functioning and services, and global environmental change impacts. In: Wall, D.H. et al. (eds.), Soil Ecology and Ecosystem Services. Oxford University Press, UK, 201-232. Wall, D.H. et al. (eds.), Soil Ecology and Ecosystem Services-_pp. 201-232. Oxford University Press.

Bunce, R.G.H., Barr, C., Gillespie, M., Howard, D., Scott, W., Smart, S., Van de Poll, H., \& Watkins, J. (1999) Vegetation of the British countryside-the Countryside Vegetation System. ECOFACT Volume 1. DETR.

Cadotte, M.W., Jonathan Davies, T., Regetz, J., Kembel, S.W., Cleland, E., \& Oakley, T.H. (2010) Phylogenetic diversity metrics for ecological communities: integrating species richness, abundance and evolutionary history. Ecology Letters, 13, 96-105.

Caruso, T., Migliorini, M., Rota, E., \& Bargagli, R. (2017) Highly diverse urban soil communities: Does stochasticity play a major role? Applied Soil Ecology, 110, 73-78.

Caruso, T., Taormina, M., \& Migliorini, M. (2011) Relative role of deterministic and stochastic determinants of soil animal community: a spatially explicit analysis of oribatid mites. Journal of Animal Ecology, 81, 214-221.

Chesson, P. (2000) Mechanisms of maintenance of species diversity. Annual Reviews in Ecology and Systematics, 31, 343-366.

Chiu, C., Wang, Y., Walther, B.A., \& Chao, A. (2014) An improved nonparametric lower bound of species richness via a modified Good-Turing frequency formula. Biometrics, 70, 671-682.

Clark, J.S. \& McLachlan, J.S. (2003) Stability of forest biodiversity. Nature, 423, 635-638.

Coleman, D.C., Crossley, D., \& Hendrix, P.F. (2004) Fundamentals of soil ecology. Academic Ppress London, UK=

Darriba, D., Taboada, G.L., Doallo, R., \& Posada, D. (2012) jModelTest 2: more models, new heuristics and parallel computing. Nature methods, 9, 772.

Davison, J., Moora, M., Öpik, M., et al. (2015) Global assessment of arbuscular mycorrhizal fungus diversity reveals very low endemism. Science, 349, 970-973.
Formatted: Font: Calibri, 11 pt, Font color: Auto

Formatted: Font: Calibri 
de Vries, F.T., Manning, P., Tallowin, J.R.B., Mortimer, S.R., Pilgrim, E.S., Harrison, K.A., Hobbs, P.J. Quirk, H., Shipley, B., Cornelissen, J.H.C., Kattge, J., \& Bardgett, R.D. (2012) Abiotic drivers and plant traits explain landscape-scale patterns in soil microbial communities. Ecology Letters, 15, 1230-1239.

Decaëns, T. (2010) Macroecological patterns in soil communities. Global Ecology and Biogeography, 19, 287-302.

Dirilgen, T., Juceviča, E., Melecis, V., Querner, P., \& Bolger, T. (2018) Analysis of spatial patterns informs community assembly and sampling requirements for Collembola in forest soils. Acta Oecologica, 86, 23-30.

Domes, K., Norton, R.A., Maraun, M., \& Scheu, S. (2007) Reevolution of sexuality breaks Dollo's law. Proceedings of the National Academy of Sciences, 104, 7139-7144.

Dray, S., Legendre, P., \& Peres-Neto, P.R. (2006) Spatial modelling: a comprehensive framework for principal coordinate analysis of neighbour matrices (PCNM). Ecological Modelling, 196, 483493.

Dumbrell, A.J., Nelson, M., Helgason, T., Dytham, C., \& Fitter, A.H. (2010) Relative roles of niche and neutral processes in structuring a soil microbial community. The ISME J, 4, 337-345.

Emmett, B., Reynolds, B., Chamberlain, P., Rowe, E., Spurgeon, D., Brittain, S., Frogbrook, Z., Hughes, S., Lawlor, A., \& Poskitt, J. (2010) Countryside survey: soils report from 2007.

Ettema, C.H. \& Wardle, D.A. (2002) Spatial soil ecology. Trends in Ecology \& Evolution, 17, 177-183.

Faith, D.P. (1992) Conservation evaluation and phylogenetic diversity. Biological conservation, 61, 110.

Fierer, N., Strickland, M.S., Liptzin, D., Bradford, M.A., \& Cleveland, C.C. (2009) Global patterns in belowground communities. Ecology Letters, 12, 1238-1249.

Firbank, L., Barr, C., Bunce, R., Furse, M., Haines-Young, R., Hornung, M., Howard, D., Sheail, J., Sier, A., \& Smart, S. (2003) Assessing stock and change in land cover and biodiversity in GB: an introduction to Countryside Survey 2000. Journal of environmental management, 67, 207218.

Giller, P.S. (1996) The diversity of soil communities, the 'poor man's tropical rainforest.' Biodiversity and Conservation, 5, 135-168.

Gotelli, N.J. \& Colwell, R.K. (2001) Quantifying biodiversity: procedures and pitfalls in the measurement and comparison of species richness. Ecology letters, 4, 379-391.

Grace, J.B. (2006) Structural equation modeling and natural systems. Cambridge University Press, Cambridge, UK

Griffiths, R.I., Thomson, B.C., James, P., Bell, T., Bailey, M., \& Whiteley, A.S. (2011) The bacterial biogeography of British soils. Environmental microbiology, 13, 1642-1654.

Guindon, S. \& Gascuel, O. (2003) A simple, fast, and accurate algorithm to estimate large phylogenies by maximum likelihood. Systematic biology, 52, 696-704. 
Hall, T.A. (1999) BioEdit: a user-friendly biological sequence alignment editor and analysis program for Windows 95/98/NT. Nucleic acids symposium series, 41, 95-98.

Hubbell, S.P. (2005) Neutral theory in community ecology and the hypothesis of functional equivalence. Functional Ecology, 19, 166-172.

Kardol, P., Martijn Bezemer, T., \& van der Putten, W.H. (2006) Temporal variation in plant-soil feedback controls succession. Ecology Letters, 9, 1080-1088.

Keith, A.M., Griffiths, R.I., Henrys, P.A., Hughes, S., Lebron, I., Maskell, L.C., Ogle, S.M., Robinson, D.A., Rowe, E.C., \& Smart, S.M. (2015) Monitoring soil natural capital and ecosystem services by using large-scale survey data. Soil Ecosystems Services.

Keith, A.M., Monson, F.D., Chaplow, J.S., Black, H.I.J., Self, P., Rollett, A., Wood, C.M. (2018). Oribatid mites 1998 [Countryside Survey] . NERC Environmental Information Data Centre. https://doi.org/10.5285/05cae9ae-86c4-4a2f-a628-6c7fd0882459

Kembel, S., Ackerly, D., Blomberg, S., Cowan, P., Helmus, M. \&Webb, C. (2008). picante: Tools for Integrating Phylogenies and Ecology, Version 0.4-0. Software package available from http://picante.r-forge.r-project.org.

Legendre, P. \& Legendre, L. (1998) Numerical Ecology. Elsevier, Amsterdam, The Netherlands.

Levine, J.M. \& HilleRisLambers, J. (2009) The importance of niches for the maintenance of species diversity. Nature, 461, 254-257.

Lindo, Z. \& Winchester, N. (2009) Spatial and environmental factors contributing to patterns in arboreal and terrestrial oribatid mite diversity across spatial scales. Oecologia, 160, 817825.

Lomolino, M.V. (2000) Ecology's most general, yet protean 1 pattern: the species-area relationship. Journal of Biogeography, 27, 17-26.

Luxton, M. (1996) Oribatid mites of the British Isles: a check-list and notes on biogeography (Acari: Oribatida). Journal of Natural History, 30, 803-822.

Maaß, S., Maraun, M., Scheu, S., Rillig, M.C., \& Caruso, T. (2015) Environmental filtering vs. resourcebased niche partitioning in diverse soil animal assemblages. Soil Biology and Biochemistry, 85, 145-152.

Maaß, S., Migliorini, M., Rillig, M.C., \& Caruso, T. (2014) Disturbance, neutral theory, and patterns of beta diversity in soil communities. Ecology and Evolution, 4, 4766-4774.

Maraun, M. \& Scheu, S. (2000) The structure of oribatid mite communities (Acari, Oribatida): patterns, mechanisms and implications for future research. Ecography, 23, 374-382.

Matheron, G. (1963) Principles of geostatistics. Economic geology, 58, 1246-1266.

Nielsen, U.N. (2014) Global-scale patterns of soil nematode assemblage structure in relation to climate and ecosystem properties. Glob. Ecol. Biogeogr., 23, 968-978.
Formatted: Font: Bold

Formatted: Highlight

Formatted: Font: +Body (Calibri), 11 pt, Font color: Auto

Formatted: Font: +Body (Calibri), 11 pt, Font color: Auto

Formatted: None

Formatted: Font: +Body (Calibri), 11 pt

Formatted: Font: (Default) +Body (Calibri), 11 pt, Underline, English (United Kingdom), Pattern: Clear (White)

Formatted: English (United States)

\section{Formatted: Normal, None}


Nielsen, U.N., Osler, G.H.R., Campbell, C.D., Neilson, R., Burslem, D.F.R.P., \& van der Wal, R. (2010) The Enigma of Soil Animal Species Diversity Revisited: The Role of Small-Scale Heterogeneity. PLOS ONE, 5, e11567.

Norton, R.A., Bonamo, P.M., Grierson, J.D., \& Shear, W.A. (1988) Oribatid mite fossils from a terrestrial Devonian deposit near Gilboa, New York. Journal of Paleontology, 62, 259-269.

O'HaraARA, R.B. (2005) Species richness estimators: how many species can dance on the head of a pin? Journal of Animal Ecology, 74, 375-386.

Oksanen, J., Kindt, R., Legendre, P., O’Hara, B., Stevens, M.H.H., Oksanen, M.J., \& Suggests, M. (2007) The vegan package. Community ecology package, 10, 631-637.

Paradis, E., Claude, J., \& Strimmer, K. (2004) APE: analyses of phylogenetics and evolution in R language. Bioinformatics, 20, 289-290.

Prober, S.M., Leff, J.W., Bates, S.T., et al. (2015) Plant diversity predicts beta but not alpha diversity of soil microbes across grasslands worldwide. Ecology Letters, 18, 85-95.

Ramirez, K.S., Leff, J.W., Barberán, A., Bates, S.T., Betley, J., Crowther, T.W., Kelly, E.F., Oldfield, E.E., Shaw, E.A., Steenbock, C., Bradford, M.A., Wall, D.H., \& Fierer, N. (2014) Biogeographic patterns in below-ground diversity in New York City's Central Park are similar to those observed globally. Proceedings of the Royal Society of London B: Biological Sciences, 281, .

-Revell, L. J. (2012) phytools: An R package for phylogenetic comparative biology (and other things). Methods in Ecology and Evolution, 3, 217-223.

Reynolds, B., Chamberlain, P., Poskitt, J., Woods, C., Scott, W., Rowe, E., Robinson, D., Frogbrook, Z., Keith, A., \& Henrys, P. (2013) Countryside Survey: National "Soil Change" 1978-2007 for Topsoils in Great Britain-acidity, carbon, and total nitrogen status. Vadose Zone Journal, 12,

Rosseel, Y. (2011) lavaan: an R package for structural equation modeling and more Version 0.4-9 (BETA).

Schaefer, I., Norton, R.A., Scheu, S., \& Maraun, M. (2010) Arthropod colonization of land - Linking molecules and fossils in oribatid mites (Acari, Oribatida). Molecular Phylogenetics and Evolution, 57, 113-121.

\section{-Schliep, K.P. (2011) phangorn: Phylogenetic analysis in R. Bioinformatics, 27(4), 592-593}

Schliep, K., Potts, A.J., Morrison, D.A., \& Grimm, G.W. (2017) Intertwining phylogenetic trees and networks. Methods in Ecology and Evolution, 8, 1212-1220.

Sheail, J. \& Bunce, R. (2003) The development and scientific principles of an environmental classification for strategic ecological survey in the United Kingdom. Environmental conservation, 30, 147-159.

Shear, W.A., Bonamo, P.M., Grierson, J.D., Rolfe, W.I., Smith, E.L., \& Norton, R.A. (1984) Early land animals in North America: evidence from Devonian age arthropods from Gilboa, New York. Science, 224, 492-494. 
Shipley, B. (2016) Cause and correlation in biology: a user's guide to path analysis, structura equations and causal inference with R. Cambridge University Press, Cambridge, UK:

Soininen, J. (2011) Macroecology of unicellular organisms - patterns and processes. Environmental Microbiology Reports, 4, 10-22.

Swenson, N.G. (2014) Functional and phylogenetic ecology in R. Springer.

Thomson, B.C., Ostle, N., McNamara, N., Bailey, M.J., Whiteley, A.S., \& Griffiths, R.I. (2010) Vegetation Affects the Relative Abundances of Dominant Soil Bacterial Taxa and Soi Respiration Rates in an Upland Grassland Soil. Microbial Ecology, 59, 335-343.

Toghil, P. (2005) The Geology of Britain: an introduction. The Crowood Press.

Van Der Heijden, M.G.A., Bardgett, R.D., \& Van Straalen, N.M. (2008) The unseen majority: soil microbes as drivers of plant diversity and productivity in terrestrial ecosystems. Ecology Letters, 11, 296-310.

Wagner, H.H. (2003) Spatial covariance in plant communities: integrating ordination, geostatistics, and variance testing. Ecology, 84, 1045-1057.

Wardle, D.A. (2006) The influence of biotic interactions on soil biodiversity. Ecology Letters, 9, 870886.

Webb, C.O. (2000) Exploring the phylogenetic structure of ecological communities: an example for rain forest trees. The American Naturalist, 156, 145-155.

Weigmann, G. (2006) Acari, Actinochaetida. Hornmilben (Oribatida). Goecke \& Evers., Keltern.

Zaitsev, A.S., Straalen, N.M. van, \& Berg, M.P. (2013) Landscape geological age explains large scale spatial trends in oribatid mite diversity. Landscape Ecology, 28, 285-296.

Data accessibility statement: The data supporting the results are available from the Environmental and Information Data Contre of NERC (UK). The spatial coordinates require a license agreement to be accessed.

\section{Biosketch}

Tancredi Caruso is a quantitative ecologist investigating the processes that structure terrestrial biodiversity in space and time

Ina Schaefer is an evolutionary biologist with expertise on soil fauna

Aidan M Keith is an ecologist investigating land use and climate impacts on soil biology and functional processes

Frank Monson is a soil animal taxonomist
Formatted: Highlight

Formatted: Highlight

Formatted: Highlight 
673 All authors developed the concept of the paper; AMK and FM compiled and collected the 674 data, TC analysed the data, IS compiled and collected molecular data and constructed the phylogenetic trees. All authors contributed substantially to the writing of the ms 


\section{Figure Legends}

Figure $1 \mathrm{a}$ ) species richness and b) Chao's estimator of species richness for each $10 \times 10$ $\mathrm{km}$ plots. The maps were obtained via kriging interpolation at the hectad scale. Red represents high values, yellow low values. Species richness (a) displays a clear latitudinal gradient with richness increasing northward along the southwest-northeast direction whereas Chao's estimator (b) displays a patchy distribution suggesting the existence of hotspots if species richness.

Figure 2 Species-area relationships for the oribatid mites of Great Britain. The three fitted models (power law, semi-log, sigmoidal) all fit the data reasonably well but the AIC criterion clearly shows that the sigmoidal model provides the best fit (blue dotted line).

Figure 3 Principal Coordinates Analysis (PCoA) ordination of oribatid mites (a). The first axis $\underline{(P C O A 1)}$ is a gradient that follow changes in mean Aggregate vegetation $\underline{\text { Vegetation Class, }}$ with more organic vegetation types and woodland soil scoring on the-positively site of PCoA1 and agricultural vegetation types (crops and grasslands) and arable soil scoring on the-negatively-side of PCOA1. This gradient is also correlated to organic matter, latitude, and precipitation, which are all positively correlated with $\mathrm{PCoA} 1-; \ln$ fact, a kriging interpolation of PCoA1 show a clear latitudinal gradient (b)

Figure 4. Kriging interpolation of three metrics of Phylogenetic Diversity. The Faith's index (a) showed gradients that were very correlated to the same ones observed for plot species richness (Fig. 1a) while Mean Pairwise Distance (MPD) and Mean Nearest Taxon Distance (MNTD) mostly reflected longitudinal gradients; although MPD reaches the highest values in 
701 the North and the East while MNTD seems more variable and reaching reaches the highest 702 value in the South-East.

Figure 5 Structural equation model linking latitude and abiotic parameters to oribatid mite species composition (PCoA1 of Fig. 3) and diversity (Faith Index PD and Mean Nearest Taxon Distance or MNTD of Fig. 4). Species richness was highly correlated to PD and was thus excluded, while MNTD and MPD returned similar results in this SEM and we selected MNTD, which provided the best fit. The model is supported by all metrics of global fit (Chisquare $=8.809$ with $9 \mathrm{df}$ and $p$-value of $0.185, \mathrm{CFI}=0.989$ and RMSEA $=0.059$ ). Figures Values besides the arrows are the path standardised coefficients. Black arrow stands for positive coefficient and gray arrows for negative coefficients. Paths statistically significant at $p$-value $<0.05$ are in bold. All paths were statistically significant except for the direct effect of

PD on MNTD and the direct effect of Latitude on PCoA 1. See also Supporting Information b for the full model output, including exact values of path coefficients, R-square values, standard deviations and statistical significance of parameter estimates. The model could account for 50, 16 and $5 \%$ of variance in PCoA 1, PD and MNTD respectively. The model could also account for 55 and $17 \%$ of variance in Organic Matter and Precipitation, respectively. 